\title{
$\therefore$ IJCRR \\ Section: Healthcare \\ Efficacy and Safety of Creatine Supplementation on Strength and Muscle Mass in Resistance Trained Individuals: A Prospective Study
} ISI Impact Factor (2019-20): 1.628 IC Value (2019): 90.81 $\operatorname{SJIF}(2020)=7.893$

(c) (i) (3)

Copyright@IJCRR

\author{
Priyanka Mirdha ${ }^{1}$, Vivek Nalgirkar ${ }^{2}$, Anant Patil ${ }^{3}$, Vijaykumar Gupta ${ }^{4}$
}

\begin{abstract}
'Assistant Lecturer, Department of Physiology, Dr. DY Patil Medical College, Navi Mumbai, Maharashtra, India; 'Professor and Head, Depart-

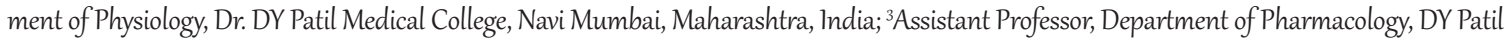
University, School of medicine, Navi Mumbai, India; ${ }^{4}$ Assistant Professor, Department of Physiology, Dr. DY Patil Medical College, Navi Mumbai, Maharashtra, India.
\end{abstract}

\section{ABSTRACT}

Introduction: Creatine is one of the widely researched nutritional supplements which increases intramuscular creatine and helps to improve training adaptations. Creatine supplement with resistance exercise also increases fat-free mass. Literature evaluating the efficacy and safety of creatine in the Indian population is sparse.

Aim: To study the efficacy and safety of creatine in improving muscle mass and strength in resistance-trained individuals.

Methodology: In this prospective, study, healthy young male (18-25 years) received a regular diet and exercise program (Control group) or creatine monohydrate $20 \mathrm{gm} /$ day for seven days and five gram/day for the next three weeks along with designed exercise program (Creatine group). Parameters for strength, body composition and body circumference measurements were recorded.

Results: Thirty participants were included. In the creatine group, the difference in the weight from baseline to day seven was significant $(62.19+5.57$ vs $63.28+5.49 \mathrm{~kg} ; \mathrm{p}<0.0001)$. The weight of participants in the creatine group increased from $62.19+5.57 \mathrm{~kg}$ at baseline to $63.28+5.49 \mathrm{~kg}$ and $65.14+5.40 \mathrm{~kg}$ after seven day and four weeks respectively $(p<0.0001)$. Performance in bench press test significantly increased in creatine group after seven days [64.0+9.14 vs 69.83+9.60 Kg (1 RM); $p<0.0001]$. Change in the arm girth $(p=0.0263)$, thigh girth $(p=0.0003)$ and calf girth $(p=0.0003)$ in the creatine group were significant over some time. No adverse events were reported in either group. Creatine was well tolerated by study participants without any adverse event.

Conclusion: Our results suggest that creatine may be effective and well-tolerated in improving muscle mass and strength in resistance-trained healthy adults.

Key Words: Creatine loading, Efficacy, Exercise, Resistance training, Safety, Strength

\section{INTRODUCTION}

With the increasing number of cases of obesity and associated diseases, the importance of physical fitness is evergrowing. ${ }^{1}$ Several interventions including diet, exercise and its combination are being tried to reduce weight and improve physical fitness. ${ }^{2}$ With increased adaptation to automation and changes in lifestyle, physical fitness awareness among the public is becoming very important. Among adults and students, sports and exercise science is gaining popularity over the years. People are becoming interested in knowing how the body responds and adapts to exercise and strategies to improve performance for enjoying a longer and healthier life.
Now a day, resistance training for sports and physical activities is gaining popularity. It provides significant functional benefits and improvement in overall health and wellbeing including increased muscular strength, muscle tone, physical appearance, enhanced endurance and bone density and increased fitness. As resistance training improves the strength of muscle, many sports adopted resistance training as part of their training regimen. Fitness enthusiast and athletes also improve their performance by using various nutritional strategies and diet. Hence, a lot of nutritional supplements are being aggressively marketed in the fitness and sports industry. Nutrition plays a pivotal role in sustaining human health, extending a healthy life span and enhances sports performance. It has been reported that a

\section{Corresponding Author:}

Dr. Priyanka Mirdha, Assistant Lecturer, Department of Physiology, Dr. DY Patil Medical College, Navi Mumbai, Maharashtra, India. Email: mirdha.priyanka@gmail.com

ISSN: 2231-2196 (Print)

Received: 06.11 .2020
ISSN: 0975-5241 (Online)

Revised: 02.01 .2021
Accepted: 18.02 .2021 
greater intake of energy with resistance training helps to increase muscle mass. ${ }^{3}$

Several nutritional supplements are readily available in the market for improving muscle mass and exercise performance. Many people practice resistance exercise training with protein supplementation for improving muscle mass. It is important to consider composition and timing of intake of protein for better results. $^{4}$

Creatine is one of the widely researched nutritional supplements. Several forms of creatine are available in the sports nutrition market. ${ }^{5}$ Creatine supplementation increases intramuscular creatine and helps to improve training adaptations. ${ }^{6,7}$ Creatine supplement with resistance exercise also increases fat-free mass. ${ }^{8}$ Creatine monohydrate is popular and one of the most commonly used ergogenic nutritional supplement. ${ }^{7,9,10}$ Creatine with heavy resistance training improves strength, fat-free mass, and muscle morphology. ${ }^{5}$ However, its supplementation does not prevent disuse atrophy in people with leg immobilization. ${ }^{11}$ Moreover, the evidence regarding creatine loading to improve muscle creatine is mixed and literature evaluating efficacy and safety of creatine in the Indian population is sparse..$^{10}$

\section{AIM}

The objective of this study was to study the efficacy and safety of creatine supplement in improving muscle mass and strength development in resistance-trained healthy individuals.

\section{METHODOLOGY}

In this prospective study, healthy young male in the age group of 18-25 years, having normal body mass index (BMI) $\left(18-23 \mathrm{~kg} / \mathrm{m}^{2}\right)$ and resistance training experience of more than one year were enrolled. Participants on any ergogenic aids and those with any acute or chronic disorders were excluded.

At baseline, the height, weight and BMI of all study participants was recorded. Standardized diet protocol was given to all participants by a registered dietician. Participants in one group (control group) received a regular diet and exercise program. Participants in another group (creatine group) received a creatine monohydrate supplement (Labrada Nutrition- CreaLean ${ }^{\mathrm{TM}} 100 \%$ Pure Creatine). Creatine was given as $20 \mathrm{gm} /$ day during the loading phase of seven days and five gram every day was given as a maintenance dose for the next three weeks along with a designed exercise program.

Participants in both groups consumed their assigned diet for consecutive seven days under supervision and regular 24 hours diet recall was done by the dietician. Exercise scientist performed exercise recall for all the subjects. All participants completed the supervised exercise sessions on five consecutive days followed by two days of no exercise before the final evaluation. All training sessions started with the warmup targeted at elevating heart rate, mobilizing joints and activating muscles for the training session. The exercise sessions consist of resistance training sessions (upper-body resistance training, lower-body resistance training and full-body resistance training) and aerobic endurance training.

The resistance training involved exercises for major muscle groups: quadriceps, hamstrings, calves, chest, back, shoulders, triceps, biceps and abs and involved the use of dumbbells, barbells, machines and cables to perform the exercises. Parameters for strength, body composition and body circumference measurements were recorded. The fat-free mass of all participants was calculated. The comparative assessment was done based on the outcome of parameters. For the assessment of strength, a one-repetition maximum bench press test and one-repetition maximum leg press test were performed whereas muscle mass was measured by circumference with measuring tape at arm, thigh and calf region.

Safety was evaluated by reporting adverse events after consumption of creatine monohydrate till the end of the study period.

The study was approved by the institutional ethics committee (Approval date: $8^{\text {th }}$ February 2018) and consent was obtained from all study participants.

\section{Statistical analysis}

Continuous variables are presented as mean and standard deviation whereas categorical variables are presented as frequency and percentages. Paired student t-test was used to compare continuous variables within the group. An unpaired student t-test was used to compare continuous variables between two groups. ANOVA test was applied to compared the difference between three-time points i.e. baseline, after one week and four weeks duration. A p-value of less than 0.05 was considered statistically significant.

\section{RESULTS}

A total of 60 participants (creatine group $n=30$; control group $n=30)$ were included in the study. The mean $(+\mathrm{SD})$ age of participants in the creatine group was $19.63( \pm 1.77)$ years. The range of age group in both groups was 18 to 24 years.

There was no difference in the mean weight between the control and creatine group at the baseline $(62.82 \pm 6.80 \mathrm{vs}$ $62.19 \pm 5.57 \mathrm{~kg} ; \mathrm{p}=0.6843)$. In the creatine group, the difference in the weight from baseline to day seven was significant $(62.19 \pm 5.57$ vs $63.28 \pm 5.49 \mathrm{~kg} ; \mathrm{p}<0.0001)$. However, there was no significant difference in weight between the control and creatine group after seven days (62.87 \pm 6.34 vs 
$63.28+5.49 \mathrm{~kg} ; \mathrm{p}=0.7933)$. The weight of participants in the creatine group increased from $62.19 \pm 5.57 \mathrm{~kg}$ at baseline to $63.28 \pm 5.49 \mathrm{~kg}$ and $65.14 \pm 5.40 \mathrm{~kg}$ after seven day and four weeks respectively. This difference was statistically significant (ANOVA; $\mathrm{p}<0.0001$; Figure 1).

In the control group, as compared to baseline there was no difference in the result of the bench press test after seven days [64.8 \pm 7.5 vs $65.2 \pm 7.5 \mathrm{Kg}(1 \mathrm{RM}) ; \mathrm{p}=0.1608]$. However, performance significantly increased in the creatine group after seven days $(64.0 \pm 9.14$ vs $69.83 \pm 9.60 ; \mathrm{p}<0.0001)$. At baseline, the difference between the control and creatine group was not significant ( $64.8 \pm 7.5$ vs $64.0 \pm 9.14 ; \mathrm{p}=0.7005$ ), but after seven days, improvement in the creatine group was statistically significant as compared to the control group $(64.2 \pm 7.5$ vs $69.83 \pm 9.60 ; p=0.0401)$. In the creatine group, there was a significant improvement in the results of the bench press test over some time $(\mathrm{p}<0.0001$; Figure 2$)$

\section{Arm, thigh and calf girth:}

In the arm girth, there was no significant difference between the control group and the creatine group at baseline $(\mathrm{p}=0.8876)$ or after seven days $(\mathrm{p}=0.8868)$. Within-group also there was no significant difference after seven days (control group $\mathrm{p}=0.0831$; creatine group $\mathrm{p}=0.0821$ ). Similarly, there was no difference between and within groups for the thigh and calf girth after 7 days (Table 1). In the creatine group, change in the arm girth $(\mathrm{p}=0.0263)$, thigh girth $(\mathrm{p}=0.0003)$ and calf girth $(p=0.0003)$ was significant over some time (Figure 3$)$. In the creatine group, the fat-free mass increased from $90.42 \pm 2.12$ to $90.51 \pm 2.10$ after 4 weeks of creatine $(\mathrm{p}<0.0001)$.

\section{DISCUSSION}

Creatine is a popular nutritional supplement used by the general population and athletes for improving performance and strength. In this study, we evaluated the efficacy and safety of creatine supplement on different parameters of strength in healthy young adults with exercise training.

Age range and body weight at baseline were similar in the creatine and control group. In the creatine group, we observed a significant increase in weight after seven days. A placebo-controlled study has also reported a significant increase in weight gain after creatine $(20 \mathrm{~g} /$ day $)$ and dextrose $180 \mathrm{~g} /$ day supplementation for five days. ${ }^{12} \mathrm{In}$ our study, after four weeks, weight in the creatine group was more than day seven. The difference over four weeks was statistically significant.

Creatine supplementation has been suggested to increase the strength of exercise by increasing intramuscular-phosphocreatine stores and promoting better recovery of adenosine triphosphate after exercise. ${ }^{13}$ In our study, after seven days of supplementation, the performance of study participants for the bench press test significantly increased in the creatine group. On the contrary in the control group, there was no significant change. Improvement in the creatine group was significantly higher than in the control group. In the creatine group, significant improvement in the bench press test was observed over four weeks. A 12-week placebo-controlled study also reported improvement in the bench press and squat performance after creatine supplementation. ${ }^{14}$

Change in the arm girth, thigh girth and calf girth was significant over some time Wang and colleagues have also shown benefits of creatine supplementation in combination with complex training on muscle parameters..$^{15}$ In a four-week placebo-controlled study, they reported improved maximal muscular strength and decreased muscle damage during training after creatine supplementation in athletes.

Creatine has the potential to improve lean body mass. ${ }^{13,14}$ In our study, participants in the creatine group, showed a significant increase in fat-free mass after four weeks. A placebocontrolled study has also reported a significant increase fat free mass after creatine ( $20 \mathrm{~g} /$ day $)$ and dextrose $180 \mathrm{~g} /$ day supplementation for five days. ${ }^{12} \mathrm{~A} 12$-week study has also reported an increase in fat free mass after creatine supplementation. ${ }^{14}$ Similar to previously reported studies we also used creatine loading followed by a maintenance dose. ${ }^{14-}$ ${ }^{16}$ The concept of loading is to increase the muscle mass by increasing muscle creatine stores and water retention in the muscle by supplementation of creatine, an osmotically active compound that helps to increase total body mass. A study reported an increase in total body water after seven days of creatine supplementation. ${ }^{17}$ It has also suggested that an increase in body mass with creatine supplementation may not be attributed to retention of water. Dry matter growth is also responsible for the increase in body mass. ${ }^{18}$

Creatine supplementation may also have an anabolic effect on the body by increasing the expression of growth factors. Supporting this view, a study has shown increased IGF mRNA in human skeletal muscle. ${ }^{19}$ These changes trigger processes resulting in the augmentation of new proteins synthesis and the development of muscle mass.

Different studies have used different dosing regimens of creatine supplementation. ${ }^{14-16}$ There are also differences in the duration of creatine use in different studies. ${ }^{14,16,20} \mathrm{Few}$ authors have studies the effect of 12-week supplementation whereas others have used it for four weeks or nine weeks. ${ }^{14-16,18,20}$

In one study, creatine monohydrate was given for four weeks. For the first two weeks, it was given as $\mathbf{3 0}$ gm per day and then $15 \mathrm{gm}$ per day for the final two weeks. ${ }^{16}$ In a study by Wang et al. loading dose of creatine was the same as that used in our study. The only difference is that, in the study by Wang and colleagues, creatine 20 gm was used for six days. ${ }^{15}$ In our study, it was used for one week. The other difference 
was in dose for maintenance. We used five gram of creatine for three weeks whereas Wang, et al used two gram per day. ${ }^{15}$ In another 12-week study, 25 gm creatine was used for one week followed by five gram per day. ${ }^{14}$

Overall, we observed significant improvements in body weight, strength (bench press test) and fat-free mass after creatine supplementation. Our observations support the beneficial effects of creatine supplementation in combination with resistance training.

Creatine is generally safe and well-tolerated by people. ${ }^{13} \mathrm{In}$ our study also, creatine supplementation given for four weeks was well tolerated by the study population. No participant in the study reported any adverse event throughout the study duration.

The single centre study, non-randomized design and small sample size study are limitations of our study. Larger, multicenter studies are recommended to confirm our observations. Moreover, it has been suggested that people with low levels of intramuscular creatine respond better to creatine supplementation. ${ }^{21}$ We did not check the intramuscular creatine levels.

\section{CONCLUSION}

The results of our study suggest that creatine can enhance strength and performance in young healthy adults. Fourweek supplementation of creatine also helps in increasing muscle mass in resistance-trained individuals.

\section{ACKNOWLEDGEMENT}

Authors acknowledge the immense help received from $\mathrm{Mr}$. Jainil Daredia, Exercise Specialist during the entire study. The authors also acknowledge the scholars whose articles are cited and included in references of this manuscript. The authors are also grateful to authors/editors/publishers of all those articles, journals and books from where the literature for this article has been reviewed and discussed.

\section{Financial support and sponsorship: NIL}

\section{Source(s) of support: NIL}

\section{Conflicting Interest (If present, give more details): NIL}

Individual author's contribution:

- Dr. Priyanka Mirdha: Study conceptualization, planning, literature search, data collection, data analysis, data interpretation, manuscript preparation, manuscript writing and manuscript approval.

- Dr. Vivek Nalgirkar: Study conceptualization, planning, literature search, data collection, data analysis, data interpretation, manuscript preparation, manuscript writing and manuscript approval.
- Dr. Anant Patil: Literature search, data interpretation, manuscript preparation, manuscript writing and manuscript approval.

- Mr. Vijaykumar Gupta: Literature search, data interpretation, manuscript preparation, manuscript writing and manuscript approval.

\section{REFERENCES}

1. Srivastava S, Dhar U, Malhotra V. Correlation between physical fitness and body mass index. Int J Cur Res Rev. 2013;5:44-48

2. Clark JE. Diet, exercise or diet with exercise: comparing the effectiveness of treatment options for weight-loss and changes in fitness for adults (18-65 years old) who are overfat, or obese; systematic review and meta-analysis. J Diabetes Metab Disord. 2015;14:31

3. Ribeiro AS, Nunes JP, Schoenfeld BJ, Aguiar AF, Cyrino ES. Effects of different dietary energy intake following resistance training on muscle mass and body fat in bodybuilders: A pilot study. J Human Kinet. 2019;17:125-134

4. Park Y, Park H-Y, Kim J, Hwang H, Jung Y, Kreider R. Effects of whey protein supplementation before, and following, resistance exercise on body composition and training responses: A randomized double-blind placebo-controlled study. J Exerc Nutrition Biochem. 2019;23:034-044

5. Cooper R, Naclerio F, Allgrove J, Jimenez A. Creatine supplementation with specific view to exercise/sports performance: an update. J Inter Soc Sports Nutr. 2012, 9:33

6. Powers ME, Arnold BL, Weltman AL, Perrin DH, Mistry D, Khahler DM, et al. Creatine supplementation increases total body water without altering fluid distribution. J Athl Train. 2003;38:44-50

7. Kreider RB, Kalman DS, Antonio J, Ziegenfuss TN, Wildman R, Collins R, et al. International Society of Sports Nutrition position stand: safety and efficacy of creatine supplementation in exercise, sport, and medicine. J Inter Soc Sports Nutr. 2017; 14:18

8. Antonio J, Ciccone V. The effects of pre versus post workout supplementation of creatine monohydrate on body composition and strength. J Inter Soc Sports Nutr. 2013, 10:36

9. Bird SP. Creatine supplementation and exercise performance: a brief review. J Sports Sci Med. 2003; 2:123-132

10. Helms ER, Aragon AA, Fitschen PJ. Evidence-based recommendations for natural bodybuilding contest preparation: nutrition and supplementation. J Inter Soc Sports Nutr. 2014, 11:20

11. Backx EMP, Hangelbroek R, Snijder T, Verscheijden M-L, Verdijk LB, de Groot LPGM, et al. Creatine loading does not preserve muscle mass or strength during leg immobilization in healthy, young males: a randomized controlled trial. Sports Med. 2017;47:1661-1671

12. Koduff LP, Vidakovic P, Cooney G, Twycross-Lewis R, Amuna $\mathrm{P}$, Parker M, et al. Effects of creatine on isometric bench-press performance in resistance-trained humans. Med Sci Sports Exerc. $2002 ; 34: 1176-83$

13. Sakkas GK, Schambelan M, Mulligan K. Can the use of creatine supplementation attenuate muscle loss in cachexia and wasting? Curr Opin Clin Nutr Metab Care. 2009; 12: 623-27

14. Volek JS, Duncan ND, Mazzetti SA, Staron RS, Putukian M, Gomez AL, et al. Performance and muscle fibre adaptations to creatine supplementation and heavy resistance training. Med Sci Sports Exerc. 1999;31:1147-56

15. Wang C-C, Fang C-C, Lee Y-H, Yang M-T, Chan K-H. Effects of 4-week creatine supplementation combined with complex 
training on muscle damage and sports performance. Nutrients. $2018 ; 10 ; 1640$

16. Kutz MR, Gunter MJ. Creatine monohydrate supplementation on body weight and per cent body fat. J Strength Cond Res. 2003; $17: 817-21$

17. Deminice R, Rosa FT, Pfrimer K, Ferrioli E, Jordao AA, Freitas E. Creatine supplementation increases total body water in soccer players: a deuterium oxide dilution study. Int J Sports Med. 2016;37:149-53

18. Francaux M, Poortmans JR. Effects of training and creatine supplement on muscle strength and body mass. Eur J Appl Physiol Occup Physiol. 1999;80:165-8
19. Deldicque L, Louis M, Theisen D, Nielens H, Dehoux M, Thissen J-P, et al. Increased IGF mRNA in human skeletal muscle after creatine supplementation. Med Sci Sports Exerc. 2005;37:731-6

20. Kreider RB, Ferreira M, Wilson M, Grindstaff P, Plisk S, Reinardy J, et al. Effects of creatine supplementation on body composition, strength, and sprint performance. Med Sci Sports Exerc. 1998;30:73-82

21. Burke DG, Chilibeck PD, Parise G, Candow DG, Mahoney D, Tarnopolsky M. Effect of creatine and weight training on muscle creatine and performance in vegetarians. Med Sci Sports Exerc. 2003;35:1946-55

\section{Table 1: Comparative effect on arm, thigh and calf girth in control and creatine group}

\section{Control group $(n=30) \quad$ Creatine group $(n=30)$}

\section{P value}

\section{Arms}

Baseline (cm)

After seven days (cm)

$P$ value

Thigh

Baseline $(\mathrm{cm})$

After seven days (cm)

$P$ value

Calf

Baseline (cm)

After seven days (cm)

$P$ value

$$
\begin{gathered}
30.53 \pm 3.2 \\
30.58 \pm 3.2 \\
0.0831 \\
47.15 \pm 5.00 \\
47.20 \pm 5.05 \\
0.1841
\end{gathered}
$$$$
33.73 \pm 3 \cdot 37
$$$$
33.77 \pm 3.39
$$

0.1608

$$
\begin{gathered}
30.43 \pm 2.18 \\
30.48 \pm 2.18 \\
0.0821
\end{gathered}
$$

0.8876

0.8868

$\begin{array}{cc}47.58 \pm 3.51 & 0.6992 \\ 47.63 \pm 3.48 & 0.7001 \\ 0.0831 & \end{array}$

$\begin{array}{cc}33.98 \pm 1.71 & 0.7187 \\ 34.03 \pm 1.73 & 0.7023 \\ 0.0831 & \end{array}$

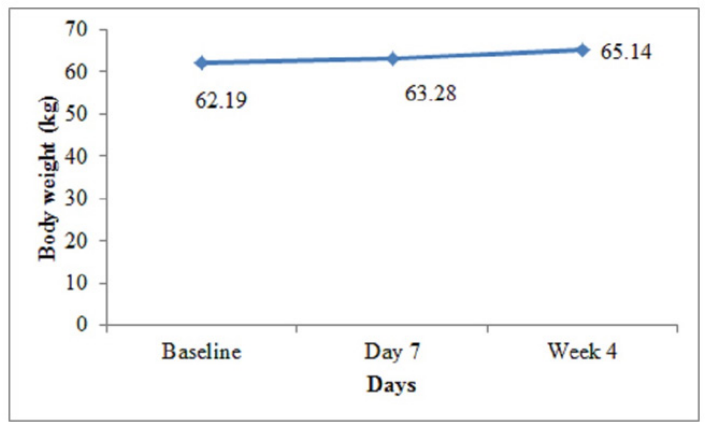

Figure 1: Effect of creatine on body weight.

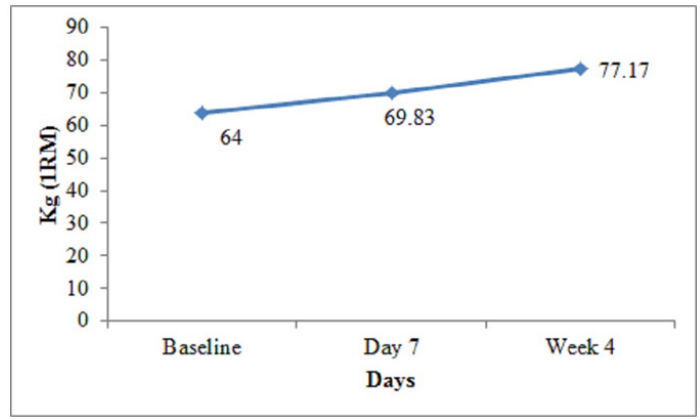

Figure 2: Improvement in bench press test in the creatine group.

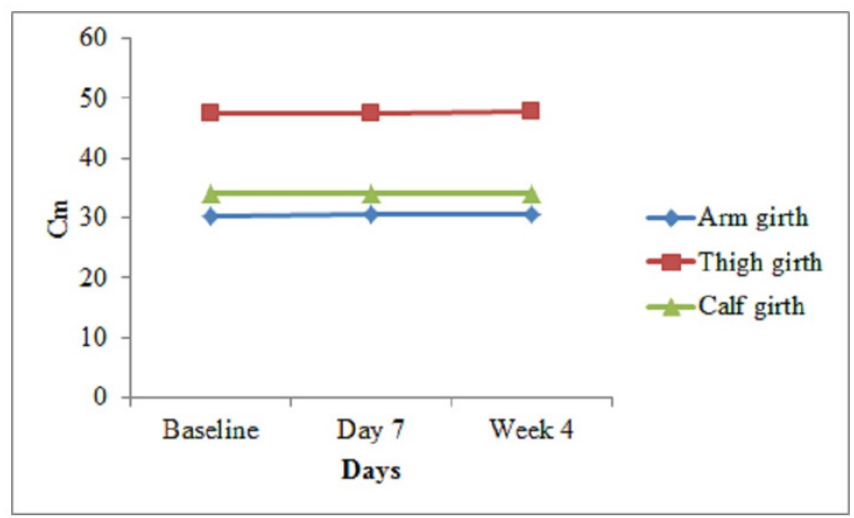

Figure 3: Change in the arm, thigh and calf girth in the creatine group. 